\title{
Deciphering deuterostome phylogeny: molecular, morphological and palaeontological perspectives
}

\author{
Billie J. Swalla ${ }^{1, *}$ and Andrew B. Smith ${ }^{2}$ \\ ${ }^{1}$ Department of Biology, University of Washington, PO Box 351800, Seattle, \\ WA 98195-1800, USA \\ ${ }^{2}$ Department of Palaeontology, The Natural History Museum, Cromwell Road, London SW7 5BD, UK
}

\begin{abstract}
Deuterostomes are a monophyletic group of animals that include the vertebrates, invertebrate chordates, ambulacrarians and xenoturbellids. Fossil representatives from most major deuterostome groups, including some phylum-level crown groups, are found in the Lower Cambrian, suggesting that evolutionary divergence occurred in the Late Precambrian, in agreement with some molecular clock estimates. Molecular phylogenies, larval morphology and the adult heart/kidney complex all support echinoderms and hemichordates as a sister grouping (Ambulacraria). Xenoturbellids are a relatively newly discovered phylum of worm-like deuterostomes that lacks a fossil record, but molecular evidence suggests that these animals are a sister group to the Ambulacraria. Within the chordates, cephalochordates share large stretches of chromosomal synteny with the vertebrates, have a complete Hox complex and are sister group to the vertebrates based on ribosomal and mitochondrial gene evidence. In contrast, tunicates have a highly derived adult body plan and are sister group to the vertebrates based on the analyses of concatenated genomic sequences. Cephalochordates and hemichordates share gill slits and an acellular cartilage, suggesting that the ancestral deuterostome also shared these features. Gene network data suggest that the deuterostome ancestor had an anterior-posterior body axis specified by Hox and Wnt genes, a dorsoventral axis specified by a $B M P /$ chordin gradient, and was bilaterally symmetrical with left-right asymmetry determined by expression of nodal.
\end{abstract}

Keywords: deuterostomes; chordate evolution; Ambulacraria

\section{INTRODUCTION}

Deuterostomes form one of the three major divisions of the Bilateria and are sister group to the Lophotrochozoa plus Ecdysozoa (Eernisse \& Peterson 2004; Philippe et al. 2005; Telford et al. 2005). Traditionally, the group was recognized on the basis of a shared embryonic development pattern: gastrulation occurs at the vegetal pole and the blastopore becomes the anus, while the mouth forms secondarily (Chea et al. 2005). Analysis of molecular data has consistently found the deuterostome grouping, generally with high levels of support (Cameron et al. 2000; Philippe et al. 2005; Delsuc et al. 2006). Five major clades make up the Deuterostomia: craniates, cephalochordates and tunicates, which together form the Chordata, along with echinoderms and hemichordates (figure 1). Because the craniates encompass all the vertebrates, including ourselves, there has long been a fascination about what the immediate invertebrate ancestors to this group were like. Theories of chordate evolution have abounded for over 100 years, but it is only in the last 10-15 years that deuterostome relationships have come into sharp focus, driven largely by new data from molecular genetics and the fossil record, and new analyses of morphological and ontogenetic data. From this plethora of information, some complementary,

\footnotetext{
* Author for correspondence (bjswalla@u.washington.edu).
}

One contribution of 17 to a Discussion Meeting Issue 'Evolution of the animals: a Linnean tercentenary celebration'. others supporting contradictory conclusions, a more coherent picture of the phylogeny and early evolution of deuterostomes is starting to emerge.

Here we review four key areas where there has been the most heated debate in the last five years: phylogenetic relationships of the major deuterostome groups; the earliest fossil record and divergence times of deuterostomes; the evolution of body axes; and the ancestral deuterostome body plan.

\section{DEUTEROSTOME PHYLOGENETIC RELATIONSHIPS}

Until the mid-1990s, based primarily on comparative adult morphology, the most widely accepted view of deuterostome relationships was that chordates and hemichordates paired together with echinoderms as their sister taxon, and that within chordates cephalochordates were closer to craniates than tunicates (i.e. (echinoderms (hemichordates (tunicates (cephalochordates + craniates)) ))). However, it had long been recognized that larval data provided support for a grouping of echinoderms and hemichordates, while palaeontological data were being used by some to support an echinoderm-chordate pairing (see reviews by Gee 1996; Lambert 2005).

With the arrival of molecular data, the prevailing view of deuterostome relationships changed. Early results, based on the analyses of ribosomal gene sequences, pointed to echinoderms and hemichordates 
as sister groups (Turbeville et al. 1994; Wada \& Satoh 1994; Cameron et al. 2000). Reassuringly, this relationship appeared to be robust to tree-building methods (Furlong \& Holland 2002) and morphological support for these groupings was forthcoming (Peterson \& Eernisse 2001). The pairing of echinoderms and hemichordates is further supported by the shared Hox gene motifs (Peterson et al. 2004), mitochondrial genes and gene arrangements (Bromham \& Degnan 1999; Lavrov \& Lang 2005) and amino acid sequences of selected nuclear genes, such as actins (Swalla 2007).

However, the monophyly of Chordata was surprisingly difficult to demonstrate with molecular data. Although craniates and cephalochordates always grouped together, tunicates proved difficult to place (Turbeville et al. 1994; Winchell et al. 2002). In some studies, tunicates were identified as sister group to Euchordates (=chordates + cephalochordates; Adoutte et al. 2000; Cameron et al. 2000), but in reality their position is unstable and varies according to which genes are used. A new group, Xenoturbellida, was also added to the deuterostomes as a member of the Ambulacraria (Bourlat et al. 2003, 2006).

In the last three years, phylogenies have increasingly been constructed from large numbers of concatenated protein-coding genes (Blair \& Hedges 2005; Philippe et al. 2005; Bourlat et al. 2006; Delsuc et al. 2006). Most of these phylogenies place echinoderms and hemichordates as sister groups, and recognize Chordata as a clade, but place tunicates, not cephalochordates, as sister group to chordates (a grouping termed Olfactores; figure 1). At the same time, an extensive cladistic reanalysis of morphological data found strong support for Olfactores (Ruppert 2005). Figure 1 summarizes the current emerging view of deuterostome relationships.

While high-level deuterostome relationships have attracted most attention, extensive progress has also been made in constructing detailed phylogenetic hypotheses for taxa within each of these major groups. A summary of echinoderm relationships was given by Smith et al. (2004) and, for the most part, both morphological and molecular data point to the same branching order. Crinoids are sister group to all other echinoderms (=Eleutherozoa) and only the position of ophiuroids with respect to other eleutherozoan taxa remains problematic (figure 1; but see Mallatt \& Winchell 2007). The match between molecules, morphology and the fossil record is particularly strong for echinoids (Smith et al. 2006).

There is less certainty about the relationships within the hemichordates. Traditionally, the group has been divided into the worm-like enteropneusts and the tubedwelling pterobranchs. However, molecular phylogenies based on ribosomal genes (Halanych et al. 1995; Cameron et al. 2000) unexpectedly found that enteropneusts were paraphyletic, with pterobranchs derived and nested among them. Zeng \& Swalla (2005) point out that solitary animals of any group will share more morphological characters than they are likely to share with colonial animals of the same group, because colonial animals tend to be reduced in body size and simplified in morphology. Thus, it is not surprising that a detailed cladistic analysis of hemichordate morphology by Cameron (2005) found strong support for pterobranchs as sister group to a monophyletic Enteropneusta. Furthermore, Winchell et al. (2002) found the position of pterobranchs varied according to which gene was being analysed, with LSU ribosomal gene data placing them as basal within hemichordates. As discussed below, understanding the dramatically different body plans of pterobranch and enteropneust hemichordates and which more closely resembles that of their latest common ancestor is critical for reconstructing the ancestral body plan of the Ambulacraria.

Zeng et al. (2006) provided a detailed $18 \mathrm{~S}$ rDNA phylogeny of tunicates that mostly complements earlier molecular and morphological analyses (Swalla et al. 2000; Yokobori et al. 2005). Within the tunicates, morphological and molecular findings are largely congruent (Cameron et al. 2000; Swalla et al. 2000; Stach \& Turbeville 2002; Winchell et al. 2002). Six separate clades of tunicates, corresponding to traditionally recognized groupings, are supported by molecular data: the ascidian clades, Stolidobranchia, Molgulidae, Phlebobranchia and Aplousobranchiata, and the pelagic tunicates, Appendicularia and Thaliacea (figure 1). The Thaliacea are all colonial and are the sister group to the Phlebobranchia plus Aplousobranchiata clade. In rRNA-based phylogenies, the solitary, pelagic, free-floating Appendicularia has a very long branch and either falls as an out-group to the rest of the tunicates (Swalla et al. 2000; Stach \& Turbeville 2002) or as a sister group to the Stolidobranchia (Yokobori et al. 2005; Zeng et al. 2006). If the tunicate ancestor resembled a member of the Appendicularia plus Stolidobranchia clade, then it would probably be solitary. However, if it resembled a member of the Phlebobranchia-Aplousobranchiata-Thaliacea clade, then it would be more likely to be colonial (Zeng \& Swalla 2005). Whatever the tunicate ancestor, the adult body plan of tunicates bears little resemblance to the fish-like body of other chordates, suggesting that major changes in the adult body plan happened early in tunicate evolution (Swalla 2006, 2007).

There are very few living cephalochordates so this group is represented by a single taxon (Brachiostoma) in most molecular analyses: a second extant genus (Epigonichthyes) is morphologically very similar (Zeng \& Swalla 2005). By contrast, extensive molecular and morphological phylogenies exist for craniates (Rowe 2004). The basal relationships of hagfish, lampreys and other jawless craniates such as conodonts have been detailed thoroughly by Donoghue et al. (2000). Molecular phylogenies based on protein-coding genes (Takezaki et al. 2003; Blair \& Hedges 2005) and ribosomal genes (Mallatt \& Sullivan 1998; Mallatt \& Winchell 2007) place hagfish and lampreys as sister taxa (Cyclostomata) and separate from all other jawed craniates.

\section{INSIGHTS FROM THE FOSSIL RECORD}

In the last 15 years, a large number of new and potentially important soft-bodied fossil deuterostomes have been recovered from the Early and Middle Cambrian deposits. However, progress has been more difficult here than for molecular studies, owing to problems arising from the incomplete preservation 


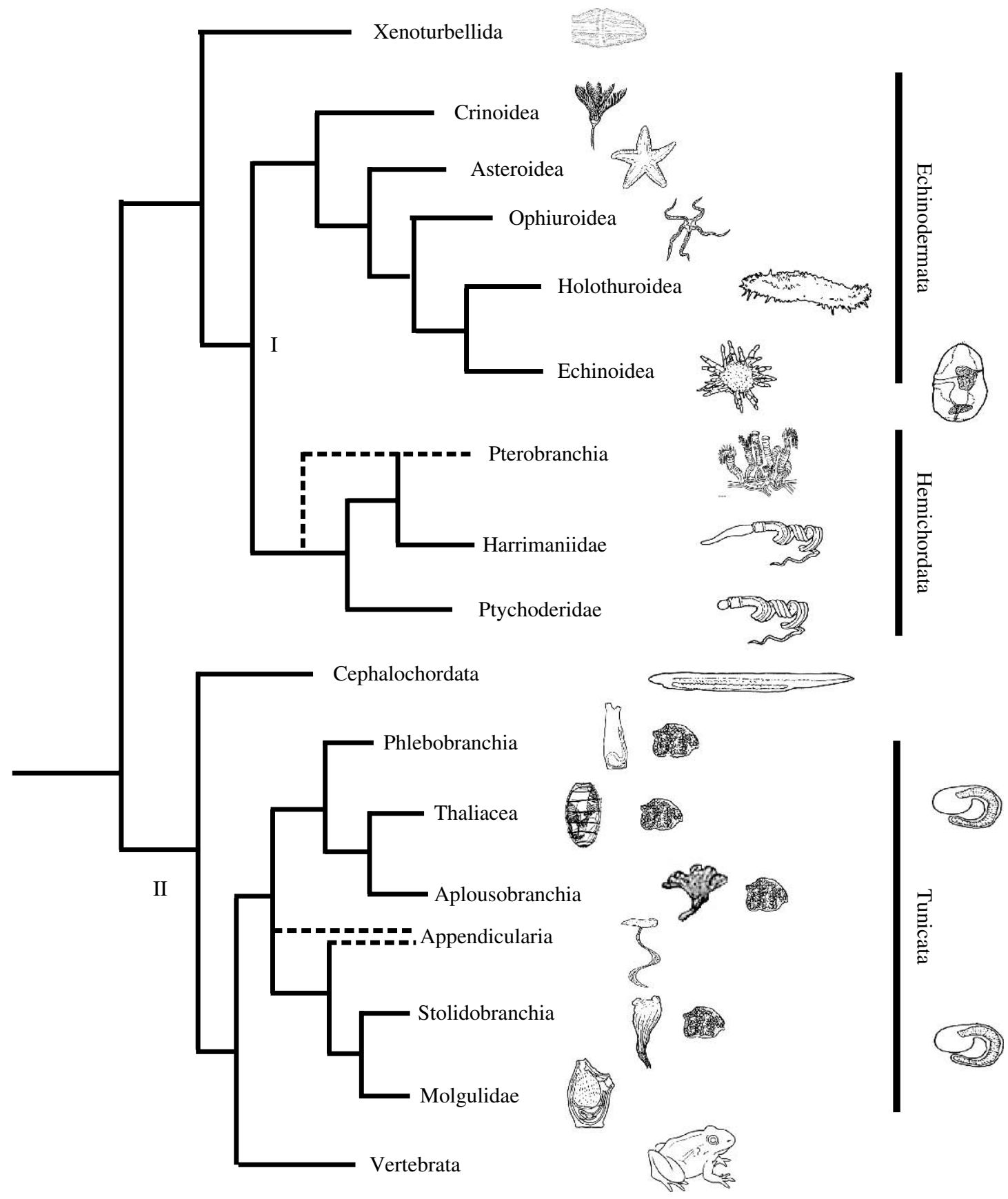

Figure 1. Current deuterostome phylogeny, according to available molecular and morphological data. Dotted lines, clades of uncertainty where conflicting data have been obtained. I and II mark clades where the evidence for a monophyletic group is very high. (I) Ambulacraria is made up of hemichordates and echinoderms. Mitochondrial, ribosomal and genomic evidence are in accord for this grouping. The Ambulacraria develop similarly through gastrulation and share larvae that feed by ciliated bands, strengthening their sister group relationship. Genomic evidence suggests that xenoturbellids may be a sister group to the Ambulacraria, but it is also possible that they are an out-group to the rest of the deuterostomes. (II) Chordates are a monophyletic group that share a specific body plan, but mitochondrial and genomic evidence are in conflict about the position of the tunicates. Mitochondrial and ribosomal evidence place cephalochordates as sister group to the vertebrates, whereas genomic evidence places tunicates as the sister group to the vertebrates. Adapted from Zeng \& Swalla (2005).

and ambiguity of interpretation. Fossils provide data on morphologies that once existed and, when included in the phylogenetic analyses with extant taxa, can aid in recognition of ancestral character states and can alter concepts of relationships by displaying character combinations not seen in living forms. However, missing data can be a major problem for the interpretation of fossils and, even with the best soft-tissue preservation in the Cambrian, we have only the outline of internal organs preserved without structural detail. Furthermore, fossil anatomy can only be interpreted through reference to extant organisms. For taxa without obvious modern counterparts (as, for example, in the case of vetulicolians discussed below), the choice of which modern organism to select as a reference for interpretation can make a huge difference. The fact that the taxonomic placement of most Cambrian soft-bodied deuterostome taxa remains disputed, attests to the difficulty of interpretation posed by these fossils.

An even more crippling problem for palaeontologists is that many of the high-ranking taxa are recognized on the basis of just a few, mostly 
embryological, biochemical or genetic characters, or from the molecular data alone (e.g. the pairing of Xenoturbella and Ambulacraria into the Xenambulacraria: Bourlat et al. 2006). Even for classes and phyla, fossils can only be placed with certainty once one or more derived morphological apomorphies have evolved, so that early stem-group members are commonly much more difficult to identify, simply because they have few emergent features! This is a general problem of ancestral taxa in the fossil record-we know that some probably exist, but we simply do not know how to identify them. Here we first review the fossil evidence for the oldest members of each phylum or subphylum and then examine whether more primitive deuterostomes, belonging to the common stem group of two or more phyla, can be definitively recognized.

\section{(a) Hemichordata}

Out of the two hemichordate morphologies, the colonial, tube-dwelling pterobranchs have by far the best fossil record. Their tubes preserve well and show two excellent synapomorphies: a characteristic fusellar structure and an internal stolon. It has long been recognized that the extinct group Graptolithina (graptolites) were a primarily planktonic group of colonial hemichordates closely related to the extant pterobranchs (Maletz et al. 2005; Rickards \& Durman 2006). Indeed, as better knowledge of the Cambrian faunas has accrued, it has become increasingly difficult to draw a clear division between pterobranchs and graptolites (Maletz et al. 2005). For example, the Ordovician Cephalodiscus-like genus Melanostrophus preserves the morphological ultrastructure of the tube in spectacular detail and displays a mixture of extant cephalodiscid and extinct graptolite features (Mierzejewski \& Urbanek 2004). It now seems that many of the primitive, benthic dendroid graptolites are probably better classified as pterobranchs (Maletz et al. 2005). Pterobranch tubes showing clear fusellar structure and an internal stolon are now recorded from the Middle Cambrian (Maletz et al. 2005; Rickards \& Durman 2006), the oldest coming from the Early Middle Cambrian (Bengtson \& Urbanek 1986). Both rhabdopleurids and cephalodiscids are present by the end of the Middle Cambrian (Rickards \& Durman 2006) showing that crown-group divergence had occurred by then.

Fossil enteropneust worms have proven to be much more elusive to identify. The most characteristic apomorphies likely to be seen in fossils are the proboscis and collar. Although Conway Morris (1979) mentions an enteropneust-like form as being present in the Burgess Shale, no convincing fossil enteropneust has yet been formally described or figured from the Cambrian. Shu et al. (1996a) initially interpreted the fossil chordate Yunnanozoon from the Lower Cambrian of China as a fossil enteropneust, but this was corrected (Shu et al. 2003a). Currently, the oldest body fossil of an enteropneust is from the Lower Jurassic of Italy (Arduini et al. 1981).

\section{(b) Echinodermata}

Echinoderms have a calcitic skeleton with a very distinctive structure termed stereom. The genes responsible for stereom deposition are unique to echinoderms (Bottjer et al. 2006). Thus, although upstream regulator genes of skeletogenesis might be common to all deuterostomes (Ettensohn et al. 2003), the specific skeletal construction of echinoderms is a reliable synapomorphy for the phylum. Furthermore, because all members of the crown group show radiate symmetry, fossils with a skeleton of stereom but without radial symmetry are best classified as stemgroup echinoderms. The morphology and relationships of stem-group echinoderms have been reviewed by Smith (2005) and some information on their soft-tissue anatomy can be deduced confidently owing to the close correspondence between stereom microstructure and investing tissue (Clausen \& Smith 2005). Stem-group echinoderms are diverse and include a variety of asymmetrical forms. These reveal that the most basal echinoderms had external gill openings, a bilaterally symmetrical muscular stalk (solutes and stylophorans) and, less certainly, a pair of tentacles and a pharyngeal basket with an atrium (cinctans; Smith 2005). The oldest skeletal elements with stereom are mid-Lower Cambrian, and both crown-group (eleutherozoan and pelmatozoan) members and stem group (solutes) are present by the latest Lower Cambrian, showing that diversification of crown-group echinoderms was already underway.

Vetulocystids, from the Late Lower Cambrian of China, were described as stem-group echinoderms by Shu et al. (2004). Three taxa were erected but two of these were badly preserved and not convincingly different from the better known Vetulocystis. Furthermore, Vetulocystis shows close similarity to vetulicolians in having a bipartite body plan with a cuticular sheath, articulated posterior appendage and at least one lateral pouch ('gill opening'). These fossils lack stereom and do not show a single echinoderm synapomorphy, so it is not clear why these were placed in the Ambulacraria.

\section{(c) Xenoturbellida}

This small-bodied taxon has no known morphological synapomorphies and lacks a skeleton. Not surprisingly, it has no known fossil record.

\section{(d) Tunicata}

There are a number of synapomorphies that should allow firm identification of tunicates from the fossil record: their tunicine cuticle; pharyngeal basket; inhalent and exhalent openings to their atrium; and endostyle. However, they are soft bodied and their fossil record is very sparse. Shu et al. (2001a) reported a fossil tunicate (Cheungkongella) from the Lower Cambrian of China, but this was based on a unique and incomplete specimen that later, with the collection of additional material, turned out to be a junior synonym of Phlogites (Chen et al. 2003; Xian-Guang et al. 2006), a taxon with paired branched tentacles whose affinities are discussed below. However, another Lower Cambrian fossil from China, Shankouclava, is a tunicate and shows typical ascidian characters, including a pharyngeal basket and possible endostyle (Chen et al. 2003). This is described as being strikingly similar to aplousobranch ascidians. The fossil record thus clearly shows that, like echinoderms, the tunicate body plan was well established by 
the Cambrian, and hints that crown-group tunicate divergence may have already occurred by the end of the Lower Cambrian.

It is also possible that the relatively diverse group of problematic Lower Cambrian fossils termed vetulicolians are appendicularian-like tunicates, but this is much less certain (Aldridge et al. 2007). The problem associated with vetulicolians is discussed in more detail below.

\section{(e) Cephalochordata}

This small group of fish-like invertebrates is readily identified from adult morphology, being jawless and having a continuous dorsal fin, myotomes, post-anal tail, barred gill slits and with a notochord that projects forward from its anterior ('head') end. Pikaia, from the Middle Cambrian Burgess Shale, and Cathaymyrus, from the Lower Cambrian of China, have both been attributed to the Cephalochordata (Shu et al. 1996b), though both remain rather poorly known.

\section{(f) Craniata}

Hagfish, lampreys and an important extinct group, the conodonts, branch close to the base of the craniate crown group (Donoghue et al. 2000). The character combinations used to place fossil members within the craniates are a well-developed brain with eyes, notochord, myotomes and gill bars or pouches. Fossil agnathan fish are present in the Lower Cambrian (Shu et al. 1999; Zhang \& Xian-Guang 2004) and show evidence of a fish-like pharynx, fins, nasal capsules and well-developed eyes (Shu et al. 2003b). Two taxa were originally described (Myllokunmingia and Haikouichthys), but subsequently these have been shown to be synonymous (Xian-Guang et al. 2002). There seems little dispute about their taxonomic affinities.

\section{(g) Potential representatives of more basal deuterostomes}

Fossil representatives of the common stem of two or more phyla are difficult to recognize with confidence because adult morphological synapomorphies are lacking. Over the last 10 years, various fossils have been championed as deuterostomes more basal than any of the five major groups, but few, if any, of these claims have stood up to detailed scrutiny. Vetulicolids (figure 2) are a clear case in point. First described as arthropods then later as basal deuterostomes, tunicates, or even possibly kinorhynchs, these animals have been the focus of much attention and debate, as reviewed recently (Aldridge et al. 2007). If vetulicolids were indeed basal deuterostomes, then they would provide critical information on the ancestral body plan. However, the recent cladistic analysis of Aldridge et al. (2007) has highlighted just how tenuous the anatomical interpretation of these fossils is. Earlier reports of a vetulicolian mesodermal skeleton (Shu et al. 2001b) are now considered unlikely. Indeed, Vetulicola itself shows clear evidence of a jointed exoskeleton, and this makes some (e.g. Caron 2006) wary of rejecting arthropod affinities, despite their apparent lack of limbs. Most have a series of 'lateral pouches' that may or may not open externally and whose detailed structure is ambiguous. These have been variously interpreted as gill slits, pouchlike arthropod gills or midgut glands. Aldridge et al. (2007) accepted these as gills but could not determine whether they had internal or external openings. A third character, the presence of an endostyle, is unprovable, because the fossilized structure in question is no more than a dark line picked out by iron oxide, it exists but its identification requires knowledge of taxonomic affinities and guesswork based on shape and position. Finally, the nature of a thin tube running to the posterior tip of the body is also critical. Shu et al. (2001b) interpret this as the gut, making the anus terminal, whereas Aldridge et al. (2007) raise the alternative possibility that it is another structure (possibly the notochord). In the face of such uncertainty, the taxonomic placement of this group remains very much in doubt.

As Lacalli (2002) and Aldridge et al. (2007) stress, vetulicolids share many similarities with tunicates, especially appendicularians, although there are still significant problems of interpretation, most notably concerning the jointed exoskeleton. Given that the interpretation of soft-tissue imprints will always remain ambiguous, it seems probable that palaeontologists will continue to have to interpret fossils in the light of theories of deuterostome origins based on the data from living organisms (contra Shu et al. 2001b).

A potential stem-group ambulacrarian, Phlogites, was recently redescribed by Xian-Guang et al. (2006). This animal has a pair of branched and erect tentacles, a large U-shaped gut and a distal muscular stalk and thus resembles a solitary pterobranch. Xian-Guang et al. (2006) compared Phlogites with various groups, noting a close similarity to uncalcified echinoderms, but eventually opting for it being a lophotrochozoan. Although Phlogites shows many features expected of a stem-group ambulacrarian, its lack of a demonstrable pharynx or obvious gill slits makes such a phylogenetic interpretation less compelling.

The ancestral chordate was likely to have been fish-like with post-anal tail, branchial bars, pharyngeal slits, a notochord and a single fin, with limited development of eyes and brain. The best contenders for representative stem-group chordates are the yunnanozoons. Yunnanozoons were originally described as cephalochordates (Chen et al. 1995), then as hemichordates (Shu et al. 1996a) and stem-group deuterostomes (Shu et al. 2003a). However, one common and well-preserved yunnanozoon, Haikouella lanceolatum, has been restudied (Mallatt \& Chen 2003; Mallatt et al. 2003), and shown to be encephalized, with a large brain, small eyes, a single fin, gill bars and filaments, and lateral myotomes. Haikouella was interpreted as a cephalochordate-like suspension feeder with an endostyle and tentacles forming a screen across the mouth. Detailed cladistic assessment (Mallatt et al. 2003) found that yunnanozoons lack any specific hagfish characters and fall closer to craniates than cephalochordates. They are thus either stem-group craniates, stem-group Olfactores or possibly late stem-group chordates. Again, the disagreement over interpretation of structures (Mallatt \& Chen 2003; Mallatt et al. 2003; Shu \& Conway Morris 2003) highlights just how tenuous soft-tissue anatomy identification in these forms can be. Basal deuterostomes are even less easy to diagnose, and no fossil has been convincingly identified. 


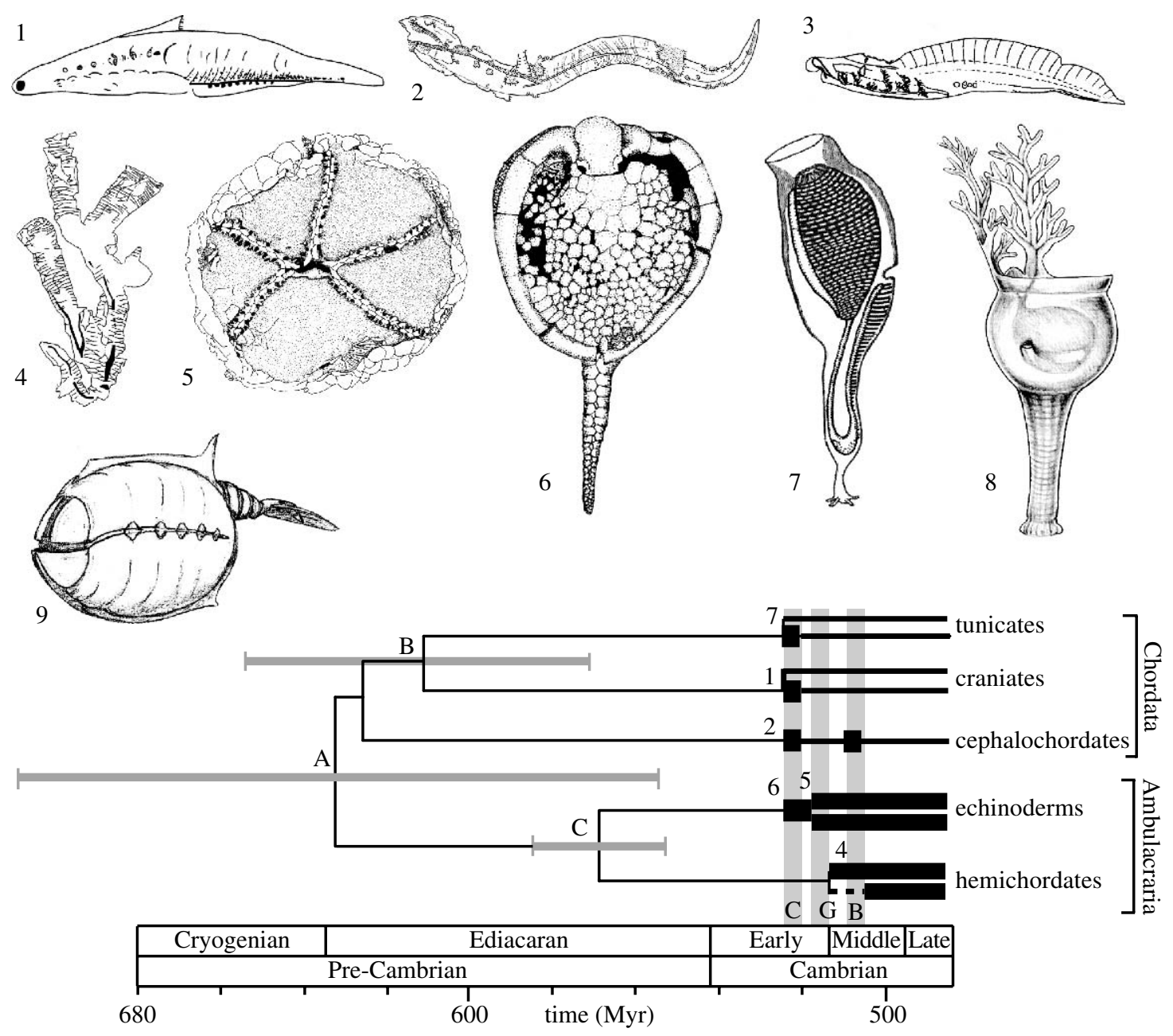

Figure 2. The fossil record of deuterostomes and molecular clock estimates of divergence times. Thick black lines, known occurrence; thin black lines, inferred range. Error bars $=95 \%$ CIs on molecular estimates. Cambrian deuterostomes and possible deuterostomes as follows (not to scale): 1, Haikouichthys (Lower Cambrian craniate); 2, Cathaymyrus (Lower Cambrian cephalochordate); 3, Haikouella (Lower Cambrian chordate; possible stem-group craniate); 4, Rhabdopleura (Middle Cambrian pterobranch); 5, Stromatocystites (Lower Cambrian crown-group echinoderm); 6, Trochocystites (Middle Cambrian stem-group echinoderm); 7, Shankouclava (Lower Cambrian ?aplousobranch ascidian tunicate); 8, Phlogites (Lower Cambrian; possible stem-group ambulacrarian); 9, Vetulicola (Lower Cambrian problematica). Molecular dating for nodes A-C as follows. A, craniate-echinoderm split based on linearized gene tree (adapted from Ayala et al. 1998); B, craniate-tunicate split based on Bayesian relaxed clock model (adapted from Douzery et al. 2004); C, Echinoderm-hemichordate split based on linearized gene tree (adapted from Peterson et al. 2004). Grey bands are deposits with soft-bodied preservation: C, Chengjiang Formation; G, Guanshan Formation; B, Burgess Shale.

In summary, the members of all five major deuterostome groups can be distinguished on adult synapomorphies by the end of the Lower Cambrian, and crown-group divergence had taken place in some (echinoderms, hemichordates and possibly tunicates). By contrast, a lack of adult morphological criteria and the general difficulty of interpreting fossils that preserve only outline traces of soft-tissue organs have meant that no common stem-group member of two or more of these groups has yet been convincingly demonstrated, except possibly yunnanozoons, whose exact position within the Chordata remains disputed.

\section{WHEN DID DEUTEROSTOME GROUPS ORIGINATE?}

The palaeontological data discussed above combined with our best molecular and morphological phylogenies demonstrate that all five major clades of deuterostomes were already present in the Lower Cambrian, $c a$ $520 \mathrm{Myr}$ ago (figure 2). Indeed, for some, crown-group divergence had already begun. Unfortunately, the fossil record tells us only about the latest time by which these groups appeared, and so we must turn to molecular data to get the estimates of their times of origin. This, however, is by no means without problems.

Most early attempts to use molecular similarity to estimate divergence times all pointed to a very deep divergence of deuterostomes (and other metazoans), predating the first fossil evidence by several hundred million years (Wray et al. 1996; Feng et al. 1997; Gu \& Li 1998; Wang et al. 1999; Nei et al. 2001). These studies all calculated divergence times assuming a single molecular rate of change across the tree calibrated using the vertebrate fossil record. However, both Ayala et al. (1998) and Peterson et al. (2004) noted that the there was a significant decrease in the rate of molecular evolution specific to vertebrates that could be misleading molecular clock estimates. To overcome this problem, Ayala et al. (1998) carefully checked for rate heterogeneity and, using a linearized 
molecular tree, calculated that chordates and echinoderms split ca $600 \mathrm{Myr}$ ago. With a similar aim, Peterson et al. (2004) calculated divergence dates after excluding vertebrates, using instead a series of calibration points drawn from the arthropod and echinoderm fossil record. This gave a minimum estimated divergence between hemichordates and echinoderms of 526-567 Myr ago (figure 2).

Recently, methods of analysis that accommodate rate variation using a 'relaxed clock' model have been developed and can produce highly convincing results, both in simulation studies and with empirical data (Ho et al. 2005; Near et al. 2005; Smith et al. 2006; Yang \& Rannala 2006), as long as the starting model used is realistic. Early application of a Bayesian relaxed clock method to the problem of metazoan divergence times by Aris-Brosou \& Yang (2003) found phylum-level splits in the Deuterostomia at ca 520-530 Myr ago, matching Peterson et al.'s (2004) results. However, they used an unrealistic model of molecular evolution in their analysis (Ho et al. 2005) and other analyses that apply potentially more appropriate models (Douzery et al. 2004) have continued to find somewhat deeper divergence dates for the Bilateria. Using a large dataset, Bayesian methodology and multiple fossil calibration points, Blair \& Hedges (2005) calculated divergence of crown-group craniates as 652 (605-742) Myr ago, divergence of Olfactores at 794 (685-918) Myr ago and divergence of Ambulacraria at 876 (725-1074) Myr ago. However, if we look at their estimates of molecular divergence within the echinoderms, where we might expect a good match with fossil evidence, even the upper CIs on molecular dates do not accord well with the fossil record. Therefore, although we know that the earliest record of deuterostome evolution is missing from the fossil record, it seems unlikely that the gap is as much as the $200 \mathrm{Myr}$ ago suggested by this study.

If we cannot be precise about the timing of the event, is it possible to determine whether diversification occurred rapidly or slowly from molecular data? Rokas et al. (2005) argued that metazoan diversification was compressed in time pointing out that, whereas fungal relationships are clearly resolved by the analysis of a large number of protein-coding genes, those of some metazoans are not. Because both groups evolved at around the same time, they reasoned that the early history of metazoans may have been a radiation compressed in time, in agreement with a direct reading of the palaeontological record. However, by increasing the number of species, replacing fast-evolving species by slowly evolving ones, and using a better model of sequence evolution, Baurain et al. (2007) found that resolution among metazoan clades was markedly improved, meaning that metazoans may not have not diversified rapidly after all. Thus, with the right models and good taxon sampling, molecular data support the idea of a relatively gradual unfolding of deuterostome diversity over time.

\section{CONSERVED GENE NETWORKS PATTERN DEUTEROSTOME AXES AND GERM LAYERS}

The Hox complex is a duplicated set of genes that frequently occur in a single cluster on the chromosome and is important for anterior-to-posterior patterning in bilaterian animals (Lemons \& McGinnis 2006). Within the deuterostomes, Hox clusters have been characterized from all of the major phylogenetic groups except xenoturbellids (Swalla 2006). It is probable that the ancestral chordate had 14 Hox genes aligned linearly along the chromosome, and that they were expressed collinearly in an anterior-to-posterior manner, as both cephalochordates and vertebrates have 14 genes, with the posterior six genes showing an independent duplication compared with protostomes (Minguillon et al. 2005; Lemons \& McGinnis 2006; Swalla 2006).

A duplication of the posterior Hox genes into three genes named Hox 11/13a, Hox 11/13b and Hox 11/13c characterizes both echinoderms and hemichordates (Peterson 2004; Morris \& Byrne 2005; Cameron et al. 2006; Lowe et al. 2006). The separate posterior genes share amino acid motifs, strongly suggesting that echinoderms and hemichordates share a common ancestor that differed from the chordate ancestor (Peterson 2004). In addition, the sea urchin (Strongylocentrotus purpuratus) genome has been sequenced (Sodergren et al. 2006) and the Hox cluster found to contain several inversions, with Hox 3 juxtaposed against Hox $11 / 13 c$, and the subsequent loss of Hox 4 (Cameron et al. 2006). The arrangement of the Hox complex in other echinoderms and hemichordates is currently unknown. However, expression of the Hox genes in the direct developer, Saccoglossus kowalevskii, has been shown to be collinear, with the anteriorposterior body axis (Aronowicz \& Lowe 2006). If the hemichordate Hox expression patterns are dependent on gene organization, then one would predict that enteropneust worms should have a single collinear cluster of Hox genes on one chromosome, similar to cephalochordates. However, if enteropneusts lack any Hox inversion, but pterobranchs and echinoderms share an inversion, then this would be a strong evidence for a pterobranch-echinoderm sister group relationship.

Hemichordates, cephalochordates and vertebrates all show collinear expression of the Hox genes in an anterior-to-posterior manner, beginning directly after the first gill slit. This suggests that the deuterostome ancestor had an anterior-posterior axis determined by the Hox complex immediately posterior to the first gill slit formed (Swalla 2006). In contrast, the chordate dorsal-ventral axis is inverted when compared with the hemichordate dorsal-ventral (D-V) axis (Ruppert 2005; Lowe et al. 2006; Swalla 2007). The hemichordate gill slits and bars are located dorsally, opposite to the ventral mouth, while in the cephalochordates and vertebrates, the gill slits and bars are located ventrally (Swalla 2007). Gill openings are also dorsal in stemgroup echinoderms (Smith 2005). Recent results have shown that the dorsal side of a juvenile hemichordate is determined by a stripe of expression of bone morphogenetic protein (BMP) gene expressed dorsally, and its ventral side by an expression stripe of BMP antagonists, including chordin (Lowe et al. 2006), just as has been reported for the arthropods (Sasai \& De Robertis 1997). By contrast, in vertebrates, BMP is expressed ventrally, and chordin is expressed dorsally (Sasai \& De Robertis 1997; Yu et al. 2007), suggesting that the chordate D-V axis is inverted compared with a hemichordate or 


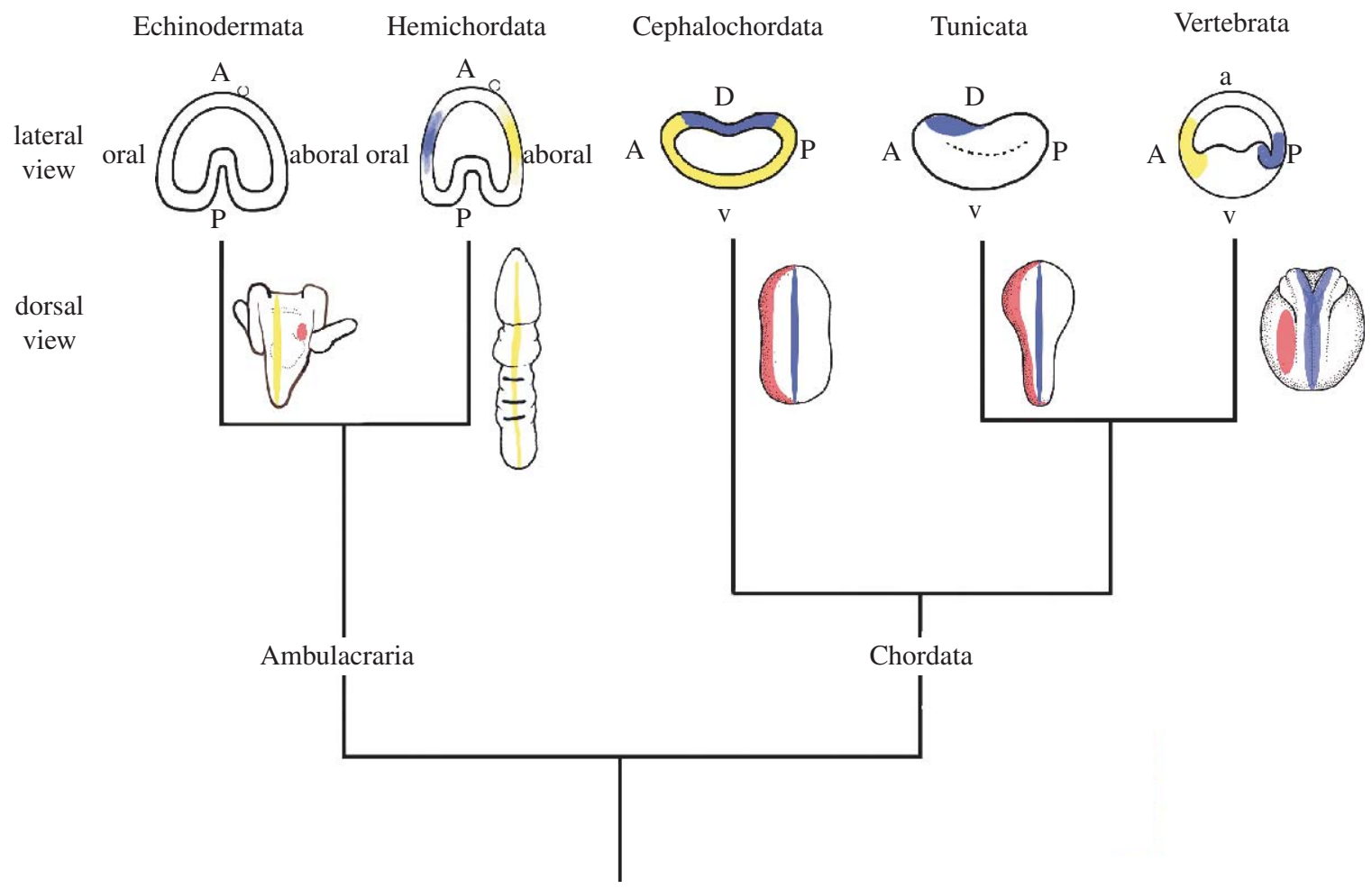

Figure 3. Summary of body axes determination in deuterostomata. A, anterior; P, posterior; a, animal; v, vegetal. Late embryonic expression of nodal is in red for all phyla. Dorsal in hemichordates is shown by BMP expression in yellow. In Echinodermata, the aboral (dorsal) axis is shown by a yellow strip, with later nodal expression marked red on the right side of the larvae, opposite of where the adult rudiment will form. Dorsal in chordates is marked in blue, while expression of chordin is shown during gastrulation in Cephalochordata, Tunicata and Craniata. The BMP-chordin axis is reversed in the chordates from the Ambulacraria. Note that later nodal expression is on the left side in the chordates, and on the right side in echinoderms. Expression patterns are adapted from Duboc et al. 2005 (urchin nodal), Lowe et al. 2006 (hemichordate chordin), Yu et al. 2007 (cephalochordate BMP and chordin), Darras \& Nishida 2001 (ascidian chordin) and Sasai \& De Robertis 1997 (frog BMP \& chordin).

arthropod D-V axis (Lowe et al. 2006). As the mouth is ventral in both the chordate and non-chordate groups, evolution of the chordates must have entailed moving the mouth from the opposite side of the gill slits to the same side as the gill slits, while also evolving a notochord and a dorsal central nervous system from a ventral enteropneust-like nerve net.

Nodal is so far one of the few described deuterostome-specific genes, evolving from the duplication of a BMP-like ancestor (Duboc et al. 2004; Chea et al. 2005). In deuterostomes, there is early nodal embryonic expression (not shown), but later nodal signalling results in left-right asymmetry of certain organs in bilateral embryos (figure 3). In all chordates, later nodal expression is on the left side during development, specifying asymmetry (Chea et al. 2005). However, in sea urchins, nodal is expressed on the right side at the later period, opposite of adult rudiment formation (Duboc et al. 2004, 2005). If nodal is likewise expressed on the right side during hemichordate development, then it would give further weight to the evidence that the Ambulacraria have a $\mathrm{D}-\mathrm{V}$ axis specified similar to flies, and that chordates have an inverted $\mathrm{D}-\mathrm{V}$ axis.

\section{WHAT WAS THE BODY PLAN OF THE EARLIEST DEUTEROSTOME?}

By combining the evidence from the most primitive fossil members of each clade with our best molecular phylogenetic hypotheses and the current ideas of homology derived from both developmental gene expression and traditional comparative morphology, we can start to build up a picture of the body plan of the earliest deuterostomes (e.g. Cameron et al. 2000; Ruppert 2005; Zeng \& Swalla 2005). Here we review the evidence relating to the latest common ancestors of Ambulacraria, Chordata and Deuterostomia.

\section{(a) Chordata}

The discovery that tunicates and craniates may be sister groups to the exclusion of cephalochordates implies that characters common to cephalochordates and craniates are ancestral to all Chordata. Thus, the chordate ancestor presumably had an intact Hox cluster that determined the anterior-posterior axis (Minguillon et al. 2005). Tunicata, distinct in many ways (Zeng \& Swalla 2005), have undergone considerable morphological and genomic simplification, including loss of metameres, nephridia and some Hox genes (Swalla 2006, 2007). If tunicates and craniates are sister taxa, then striated heart muscle and neural crest-like tissue were present in their latest common ancestor (Jeffery et al. 2004). Based on the shared features between cephalochordates and craniates, the latest common ancestor of all chordates might be expected to be a worm-like segmented organism with metamerism and myotomes, a dorsal notochord, dorsal hollow nerve, pharyngeal mucous net filtration with endostyle, undivided fins, locomotory post-anal tail, a pre-oral hood and a hepatic portal system (Ruppert 2005; Swalla 2007). 
As neither Ambulacraria nor cephalochordates have a well-developed brain, encephalization may have been limited and sensory facilities poorly developed in the very earliest chordates. However, the absence of some sensory systems in cephalochordates may be secondary if Haikouella, with its small eyes and encephalization, represents a late stem-group chordate. Reproduction was probably through direct development.

\section{(b) Ambulacraria}

Living echinoderms are so highly derived compared with other deuterostomes that meaningful comparisons of adult body plans have been more or less futile. Even determining the anterior-posterior axis in adult echinoderms has proved difficult until recently (Peterson et al. 2000; Swalla 2006; Morris 2007). However, with the inclusion of pre-radiate fossil echinoderms, comparison is greatly simplified and clarified. There is a clear anterior-posterior axis, and structures that have been lost from all crown-group echinoderms, such as the pharyngeal openings and muscular stalk, are present (Smith 2005). There is another problem, however, and that is determining whether the enteropneust or pterobranch body plan is primitive for hemichordates. Because lophophorates were once considered as ancestral to deuterostomes, the pterobranch body plan, with its lophophore-like tentacles, has traditionally been taken as primitive for deuterostomes (Gee 1996). More recently, however, the enteropneust model has been suggested because the anterior-posterior and dorsal-ventral axes in the enteropneust hemichordates are determined by similar genetic pathways to the chordates (Cameron et al. 2000; Zeng \& Swalla 2005) and because the enteropneust pharynx is very similar to that of cephalochordates (Ruppert 2005). However, echinoderms and pterobranchs share a muscular stalk used for attachment and locomotion, a hollow, branched tentacular system derived from the same mesocoel and used for the same purpose, so these features would instead favour a stalked, tentaculate form resembling the fossil Phlogites rather than a worm-like form as the latest common ancestor.

Irrespective of whether an enteropneust or pterobranch body plan is ancestral to hemichordates, the latest common ancestor of echinoderms and hemichordates is expected to have had a diffuse nerve network, no mesodermal skeleton, tricoelomic development, a planktotrophic dipleurula larva and metamorphosis, a nephridial system and pharyngeal gill slits.

\section{(c) Deuterostomia}

There are three competing models for how the latest common ancestor to the deuterostome body was constructed: an ambulacrarian model; a chordate model; or a xenoturbellid model. Given this uncertainty, it is not yet clear whether ancestral developmental mode would have been direct or indirect. Although both tunicates and ambulacrarians have larvae that are planktotrophic, they are very different in form and in the gene networks that are deployed during development (Swalla 2006). Echinoderm and hemichordate dipleurula-type larvae feed using ciliary bands and are undoubtedly homologous (Hara et al. 2006). The nonfeeding tunicate larva is very different and clearly non-homologous, being tadpole-like and sharing derived body plan features with vertebrates, including a notochord centred in the tail flanked dorsally by the nerve cord, laterally by muscles and ventrally by endoderm (Swalla 2007). Both types of larvae presumably evolved independently in the Late Precambrian at a time when the ocean surface waters were becoming rich in phytoplankton for the first time and benthic predation was dramatically increasing (Butterfield 2007).

(i) Given Xenoturbella's phylogenetic position as basal to Ambulacraria (Bourlat et al. 2003, 2006), it is possible that the latest common ancestor to deuterostomes was a small delicate, ciliated marine worm with a simple body plan lacking a through gut, organized gonads, excretory structures and coelomic cavities. Although this would accord with why deuterostomes may have had a long hidden history according to molecular clocks (e.g. Davidson et al. 1995) and may indeed pertain to the latest common ancestor of deuterostomes and protostomes, it is definitely not parsimonious to have shared derived features, such as pharyngeal feeding and gill slits, a postanal muscular tail or stalk evolving independently in chordates and Ambulacraria, and such features were surely present in the latest members of their common stem group. Xenoturbella is thus not an appropriate model for the latest common ancestor of extant deuterostomes.

(ii) The latest common ancestor of deuterostomes might have been a benthic filter-feeding worm with gill slits similar to extant enteropneust worms (Cameron et al. 2000). It would have had a simple nerve plexus without regionalization, a pharynx with gill slits used in filter feeding, well-developed circular and longitudinal muscles and direct development. This would imply that tentacles evolved independently from the mesocoel in echinoderms and colonial pterobranchs.

(iii) Finally, a tentaculate pterobranch-like organism has long been a popular model for the primitive deuterostome based on the idea that hemichordates were primitive and lophophorates were their sister group (Romer 1967). With modern molecular phylogenies, this has become less popular. However, it cannot be entirely dismissed if the latest common ancestor to Ambulacraria was pterobranch like rather than enteropneust like.

Special thanks go to Carolyn McCann and Hee Sun Kim who together constructed figure 3. Mariko Bushcamp is thanked for collating references and all three undergraduates in the Swalla Laboratory are thanked for reading the manuscript and suggesting changes. Jon Mallatt and an anonymous reviewer provided many helpful suggestions and constructive criticisms that have greatly improved the paper. Dr Elena Keeling and Amanda Rychel are also thanked for their critical reading of the manuscript.

\section{REFERENCES}

Adoutte, A., Balavoine, G., Lartillot, N., Lespinet, O., Prud'homme, B. \& de Rosa, R. 2000 The new animal phylogeny: reliability and implications. Proc. Natl Acad. Sci. USA 97, 4453-4456. (doi:10.1073/pnas.97.9.4453) 
Aldridge, R. J., Xian-guang, H., Siveter, D. J. \& Gabbott, S. E. 2007 The systematics and phylogenetic relationships of vetulicolians. Palaeontology 50, 131-168. (doi:10.1111/ j.1475-4983.2006.00606.x)

Arduini, P., Pinna, G. \& Teruzzi, G. 1981 Megaderaion sinemuriense, a new fossil enteropneust of the Sinemurian. Atti Soc. Ital. Sci. Nat. Mus. Civ. Storia Nat. Milano 122, 104-108.

Aris-Brosou, S. \& Yang, Z. 2003 Bayesian models of episodic evolution support a Late Precambrian explosive diversification of the Metazoa. Mol. Biol. Evol. 20, 1947-1954. (doi:10.1093/molbev/msg226)

Aronowicz, J. \& Lowe, C. J. 2006 Hox gene expression in the hemichordate Saccoglossus kowalevskii and the evolution of deuterostome nervous systems. Integr. Comp. Biol. 46, 890-901. (doi:10.1093/icb/icl045)

Ayala, F. J., Rzhetsky, A. \& Ayala, F. J. 1998 Origin of the metazoan phyla: molecular clocks confirm paleontological estimates. Proc. Natl Acad. Sci. USA 95, 606-611. (doi:10. 1073/pnas.95.2.606)

Baurain, D., Brinkmann, H. \& Philippe, H. 2007 Lack of resolution in the animal phylogeny: closely spaced cladogeneses or undetected systematic errors? Mol. Biol. Evol. 24, 6-9. (doi:10.1093/molbev $/ \mathrm{msl137}$ )

Bengtson, S. \& Urbanek, A. 1986 Rhabdotubus, a Middle Cambrian rhabdopleurid hemichordate. Lethaia 19, 293-308. (doi:10.1111/j.1502-3931.1986.tb00743.x)

Blair, J. E. \& Hedges, S. B. 2005 Molecular phylogeny and divergence times of deuterostome animals. Mol. Biol. Evol. 22, 2275-2284. (doi:10.1093/molbev/msi225)

Bottjer, D. J., Davidson, E. H., Peterson, K. J. \& Cameron, R. A. 2006 Paleogenomics of echinoderms. Science 314, 956-960. (doi:10.1126/science.1132310)

Bourlat, S. J., Nielsen, C., Lockyer, A. E., Littlewood, D. T. J. \& Telford, M. J. 2003 Xenoturbella is a deuterostome that eats molluscs. Nature 424, 925-928. (doi:10.1038/nature01851)

Bourlat, S. J. et al. 2006 Deuterostome phylogeny reveals monophyletic chordates and the new phylum Xenoturbellida. Nature 444, 85-88. (doi:10.1038/nature05241)

Bromham, L. D. \& Degnan, B. M. 1999 Hemichordates and deuterostome evolution: robust molecular phylogenetic support for a hemichordate+echinoderm clade. Evol. Dev. 1, 166-171. (doi:10.1046/j.1525-142x.1999.99026.x)

Butterfield, N. J. 2007 Macroevolution and macroecology through deep time. Palaeontology 50, 41-55. (doi:10.1111/ j.1475-4983.2006.00613.x)

Cameron, C. B. 2005 A phylogeny of the hemichordates based on morphological characters. Can. F. Zool. 83, 196-215. (doi:10.1139/z04-190)

Cameron, C. B., Garey, J. R. \& Swalla, B. J. 2000 Evolution of the chordate body plan: new insights from phylogenetic analyses of deuterostome phyla. Proc. Natl Acad. Sci. USA 97, 4469-4474. (doi:10.1073/pnas.97.9.4469)

Cameron, R. A. et al. 2006 Unusual gene order and organization of the sea urchin hox cluster. F. Exp. Zool. B: Mol. Dev. Evol. 306, 45-58. (doi:10.1002/jez.b.21070)

Caron, J. B. 2006 Banffia constricta, a putative vetulicolid from the Middle Cambrian Burgess Shale. Trans. R. Soc. Edin. 96, 95-111.

Chea, H. K., Wright, C. V. \& Swalla, B. J. 2005 Nodal signaling and the evolution of deuterostome gastrulation. Dev. Dyn. 234, 269-278. (doi:10.1002/dvdy.20549)

Chen, J.-Y., Dzik, J., Edgecombe, G. D., Ramskold, L. \& Zhou, G.-Q. 1995 A possible Early Cambrian chordate. Nature 377, 720-722. (doi:10.1038/377720a0)

Chen, J.-Y., Huang, D.-Y., Peng, Q.-Q., Chi, H.-M., Wang, X.-Q. \& Feng, M. 2003 The first tunicate from the Early Cambrian of South China. Proc. Natl Acad. Sci. USA 100, 8314-8318. (doi:10.1073/pnas.1431177100)
Clausen, S. \& Smith, A. B. 2005 Palaeoanatomy and biological affinities of a Cambrian deuterostome (Stylophora). Nature 438, 351-354. (doi:10.1038/nature04109)

Conway Morris, S. 1979 The Burgess Shale (Middle Cambrian) fauna. Annu. Rev. Ecol. Syst. 10, 327-349. (doi:10.1146/annurev.es.10.110179.001551)

Darras, S. \& Nishida, H. 2001 The BMP/CHORDIN antagonism controls sensory pigment cell specification and differentiation in the ascidian embryo. Dev. Biol. 236, 271-288. (doi:10.1006/dbio.2001.0339)

Davidson, E. H., Peterson, K. J. \& Cameron, R. A. 1995 Origin of bilaterian body plans: evolution of developmental regulatory mechanisms. Science , 1319-1325. (doi10.1126/ science.270.5240.1319)

Delsuc, F., Brinkmann, H., Chourrout, D. \& Philippe, H. 2006 Tunicates and not cephalochordates are the closest living relatives of vertebrates. Nature 439, 965-968. (doi:10. 1038/nature04336)

Donoghue, P. C. J., Forey, P. L. \& Aldridge, R. J. 2000 Conodont affinity and chordate phylogeny. Biol. Rev. 75, 191-251. (doi:10.1017/S0006323199005472)

Douzery, E. J., Snell, E. A., Bapteste, E., Delsuc, F. \& Philippe, H. 2004 The timing of eukaryotic evolution: does a relaxed molecular clock reconcile proteins and fossils? Proc. Natl Acad. Sci. USA 101, 15 386-15 391. (doi:10.1073/pnas. 0403984101)

Duboc, V., Rottinger, E., Besnardeau, L. \& Lepage, T. 2004 Nodal and BMP2/4 signaling organizes the oral-aboral axis of the sea urchin embryo. Dev. Cell 6, 397-410. (doi:10. 1016/S1534-5807(04)00056-5)

Duboc, V., Rottinger, E., Lapraz, F., Besnardeau, L. \& Lepage, T. 2005 Left-right asymmetry in the sea urchin embryo is regulated by nodal signaling on the right side. Dev. Cell $\mathbf{9}$, 147-158. (doi:10.1016/j.devcel.2005.05.008)

Eernisse, D. J. \& Peterson, K. J. 2004 The history of animals. In Assembling the tree of life (eds J. Cracraft \& M. J. Donoghue), Oxford, UK: Oxford University Press.

Ettensohn, C. A., Illies, M. R., Oliveri, P. \& De Jong, D. L. 2003 Alx1, a member of the Cart1/Alx3/Alx4 subfamily of paired-class homeodomain proteins, is an essential component of the gene network controlling skeletogenic fate specification in the sea urchin embryo. Development 130, 2917-2928. (doi:10.1242/dev.00511)

Feng, D. F., Cho, G. \& Doolittle, R. F. 1997 Determining divergence times with a protein clock: update and reevaluation. Proc. Natl Acad. Sci. USA 94, 13 028-13 033. (doi:10. 1073/pnas.94.24.13028)

Furlong, R. F. \& Holland, P. W. 2002 Bayesian phylogenetic analysis supports monophyly of Ambulacraria and of cyclostomes. Zool. Sci. 19, 593-599. (doi:10.2108/zsj.19.593)

Gee, H. 1996 Before the backbone. Views on the origin of the vertebrates. London, UK: Chapman and Hall.

Gu, X. \& Li, W. H. 1998 Estimation of evolutionary distances under stationary and nonstationary models of nucleotide substitution. Proc. Natl Acad. Sci. USA 95, 5899-5905. (doi:10.1073/pnas.95.11.5899)

Halanych, K. M., Bacheller, J. D., Aguinaldo, A. M. A., Liva, S. M., Hillis, D. M. \& Lake, J. A. 1995 Evidence from 18S ribosomal DNA that the lophophorates are protostome animals. Science 267, 1641-1642. (doi:10.1126/science. 7886451)

Hara, Y., Yamaguchi, M., Akasaka, K., Nakano, H., Nonaka, M. \& Amemiya, S. 2006 Expression patterns of Hox genes in larvae of the sea lily Metacrinus rotundus. Dev. Genes Evol. 216, 797-809. (doi:10.1007/s00427-006-0108-1)

Ho, S. Y., Phillips, M. J., Drummond, A. J. \& Cooper, A. 2005 Accuracy of rate estimation using relaxed-clock models with a critical focus on the early metazoan radiation. Mol. Biol. Evol. 22, 1355-1363. (doi:10.1093/molbev/msi125) 
Jeffery, W. R., Strickler, A. G. \& Yamamoto, Y. 2004 Migratory neural crest-like cells form body pigmentation in a urochordate embryo. Nature 431, 696-699. (doi:10.1038/ nature02975)

Lacalli, T. C. 2002 Vetulicolians - are they deuterostomes? chordates? Bioessays 24, 208-211. (doi:10.1002/bies.10064)

Lambert, C. C. 2005 Historical introduction, overview, and reproductive biology of protochordates. Can. F. Zool. 83, 1-7. (doi:10.1139/z04-160)

Lavrov, D. V. \& Lang, B. F. 2005 Poriferan mtDNA and animal phylogeny based on mitochondrial gene arrangements. Syst. Biol. 54, 651-659. (doi:10.1080/10635150500221044)

Lemons, D. \& McGinnis, W. 2006 Genomic evolution of $H o x$ gene clusters. Science 313, 1918-1922. (doi:10.1126/ science.1132040)

Lowe, C. J. et al. 2006 Dorsoventral patterning in hemichordates: insights into early chordate evolution. PLoS Biol. 4, e291. (doi:10.1371/journal.pbio.0040291)

Maletz, J., Steiner, M. \& Fatka, O. 2005 Middle Cambrian pterobranchs and the question: what is a graptolite? Lethaia 38, 73-85. (doi:10.1080/00241160510013204)

Mallatt, J. \& Chen, J.-Y. 2003 Fossil sister group of craniates: predicted and found. F. Morphol. 258, 1-31. (doi:10.1002/ jmor.10081)

Mallatt, J. \& Sullivan, J. 1998 28S and 18S rDNA sequences support the monophyly of lampreys and hagfishes. Mol. Biol. Evol. 15, 1706-1718.

Mallatt, J. \& Winchell, C. J. 2007 Ribosomal RNA genes and deuterostome phylogeny revisited: more cyclostomes, elasmobranchs, reptiles, and a brittle star. Mol. Phylogenet. Evol. 43, 1005-1022. (doi:10.1016/j.ympev.2006.11.023)

Mallatt, J., Chen, J. \& Holland, N. D. 2003 Comment on "a new species of yunnanozoan with implications for deuterostome evolution". Science 300, 1372. (doi:10.1126/ science.1085064)

Mierzejewski, P. \& Urbanek, A. 2004 The morphology and fine structure of the Ordovician Cephalodiscus-like genus Melanostrophus. Acta Palaeontol. Pol. 49, 519-528.

Minguillon, C., Gardenyes, J., Serra, E., Castro, L. F., HillForce, A., Holland, P. W., Amemiya, C. T. \& GarciaFernandez, J. 2005 No more than 14: the end of the amphioxus Hox cluster. Int. F. Biol. Sci. 1, 19-23.

Morris, V. B. 2007 Origins of radial symmetry identified in an echinoderm during adult development and the inferred axes of ancestral bilateral symmetry. Proc. R. Soc. B 274, 1511-1516. (doi:10.1098/rspb.2007.0312)

Near, T. J., Meylan, P. A. \& Shaffer, H. B. 2005 Assessing concordance of fossil calibration points in molecular clock studies: an example using turtles. Am. Nat. 165, 137-146. (doi: $10.1086 / 427734$ )

Nei, M., Xu, P. \& Glazko, G. 2001 Estimation of divergence times from multiprotein sequences for a few mammalian species and several distantly related organisms. Proc. Natl Acad. Sci. USA 98, 2497-2502. (doi:10.1073/ pnas.051611498)

Peterson, K. J. 2004 Isolation of Hox and Parahox genes in the hemichordate Ptychodera flava and the evolution of deuterostome Hox genes. Mol. Phylogenet. Evol. 31, 1208-1215. (doi:10.1016/j.ympev.2003.10.007)

Peterson, K. J. \& Eernisse, D. J. 2001 Animal phylogeny and the ancestry of bilaterians: inferences from morphology and 18S rDNA gene sequences. Evol. Dev. 3, 170-205. (doi:10. 1046/j.1525-142x.2001.003003170.x)

Peterson, K. J., Arenas-Mena, C. \& Davidson, E. H. 2000 The $\mathrm{A} / \mathrm{P}$ axis in echinoderm ontogeny and evolution: evidence from fossils and molecules. Evol. Dev. 2, 93-101. (doi:10. 1046/j.1525-142x.2000.00042.x)

Peterson, K. J., Lyons, J. B., Nowak, K. S., Takacs, C. M., Wargo, M. J. \& McPeek, M. A. 2004 Estimating metazoan divergence times with a molecular clock. Proc. Natl Acad. Sci. USA 101, 6536-6541. (doi:10.1073/pnas.0401670101)

Philippe, H., Lartillot, N. \& Brinkmann, H. 2005 Multigene analyses of bilaterian animals corroborate the monophyly of Ecdysozoa, Lophotrochozoa, and Protostomia. Mol. Biol. Evol. 22, 1246-1253. (doi:10.1093/molbev/msi111)

Rickards, B. \& Durman, P. N. 2006 Evolution of the earliest graptolites and other hemichordates. In Studies in Palaeozoic palaeontology, vol. 25 (eds M. G. Bassett \& V. K. Deisler) National museum of Wales geological series, p. 294. Wales, UK: National Museum of Wales.

Rokas, A., Kruger, D. \& Carroll, S. B. 2005 Animal evolution and the molecular signature of radiations compressed in time. Science 310, 1933-1938. (doi:10.1126/science.1116759)

Romer, A. S. 1967 Major steps in vertebrate evolution. Science 158, 1629-1637. (doi:10.1126/science.158.3809.1629)

Rowe, T. 2004 Chordate phylogeny and development. In Assembling the tree of life (eds J. Cracraft \& M. J. Donoghue), pp. 384-409. Oxford, UK: Oxford University Press.

Ruppert, E. E. 2005 Key characters uniting hemichordates and chordates: homologies or homoplasies. Can. F. Zool. 83, 8-23. (doi:10.1139/z04-158)

Sasai, Y. \& De Robertis, E. M. 1997 Ectodermal patterning in vertebrate embryos. Dev. Biol. 182, 5-20. (doi:10.1006/ dbio. 1996.8445)

Shu, D. \& Conway Morris, S. 2003 Response to comment on "a new species of yunnanozoan with implications for deuterostome evolution”. Science 300, 1372. (doi:10.1126/ science.1085573)

Shu, D.-G., Zhang, X.-L. \& Chen, L. $1996 a$ Reinterpretation of Yunnanozoon as the earliest known hemichordate. Nature 380, 428-430. (doi:10.1038/380428a0)

Shu, D.-G., Conway Morris, S. \& Zhang, X. L. $1996 b$ A Pikaia-like chordate from the Lower Cambrian of China. Nature 384, 157-158. (doi:10.1038/384157a0)

Shu, D.-G., Conway Morris, S., Zhang, X. L., Hu, S.-X., Chen, L., Han, J., Zhu, M., Li, Y. \& Chen, L.-Z. 1999 Lower Cambrian vertebrates from south China. Nature 402, 42-46. (doi:10.1038/46965)

Shu, D.-G., Chen, L., Han, J. \& Zhang, X. L. 2001 a An Early Cambrian tunicate from China. Nature 411, 472-473. (doi:10.1038/35078069)

Shu, D.-G., Conway Morris, S., Han, J., Chen, L., Zhang, X. L., Zhang, Z. F., Liu, H. Q., Li, Y. \& Liu, J. N. $2001 b$ Primitive deuterostomes from the Chengjiang Lagerstatte (Lower Cambrian, China). Nature 414, 419-424. (doi:10. 1038/35106514)

Shu, D.-G., Conway Morris, S., Zhang, Z. F., Liu, J. N., Han, J., Chen, L., Zhang, X. L., Yasui, K. \& Li, Y. 2003a A new species of yunnanozoan with implications for deuterostome evolution. Science 299, 1380-1384. (doi:10.1126/science. 1079846)

Shu, D.-G. et al. $2003 \mathrm{~b}$ Head and backbone of the Early Cambrian verterbate Haikouichthys. Nature 421, 526-529. (doi:10.1038/nature01264)

Shu, D.-G., Conway Morris, S., Han, J., Zhang, Z. F. \& Liu, J. N. 2004 Ancestral echinoderms from the Chengjiang deposits of China. Nature 430, 422-428. (doi:10.1038/ nature02648)

Smith, A. B. 2005 The pre-radial history of echinoderms. Geol. f. 40, 255-280. (doi:10.1002/gj.1018)

Smith, A. B., Peterson, K. J., Wray, G. \& Littlewood, D. T. J. 2004 From bilateral symmetry to pentaradiality: the phylogeny of hemichordates and echinoderms. In Assembling the tree of life (eds J. Cracraft \& M. J. Donoghue), pp. 365-383. New York, NY: Oxford University Press.

Smith, A. B., Pisani, D., Mackenzie-Dodds, J. A., Stockley, B., Webster, B. L. \& Littlewood, D. T. J. 2006 Testing the molecular clock: molecular and paleontological estimates of 
divergence times in the Echinoidea (Echinodermata). Mol. Biol. Evol. 23, 1832-1851. (doi:10.1093/molbev/msl039)

Sodergren, E. et al. 2006 The genome of the sea urchin Strongylocentrotus purpuratus. Science 314, 941-952. (doi:10. 1126/science.1133609)

Stach, T. \& Turbeville, J. M. 2002 Phylogeny of Tunicata inferred from molecular and morphological characters. Mol. Phylogenet. Evol. 25, 408-428. (doi:10.1016/S10557903(02)00305-6)

Swalla, B. J. 2006 Building divergent body plans with similar genetic pathways. Heredity 97, 235-243. (doi:10.1038/ sj.hdy.6800872)

Swalla, B. J. 2007 New insights into vertebrate origins. In Principles of developmental genetics (ed. S. Moody), pp. 114-128. London, UK: Academic Press.

Swalla, B. J., Cameron, C. B., Corley, L. S. \& Garey, J. R. 2000 Urochordates are monophyletic within the deuterostomes. Syst. Biol. 49, 52-64. (doi:10.1080/1063515005 0207384)

Takezaki, N., Figueroa, F., Zaleska-Rutczynska, Z. \& Klein, J. 2003 Molecular phylogeny of early vertebrates: monophyly of the agnathans as revealed by sequences of 35 genes. Mol. Biol. Evol. 20, 287-292. (doi:10.1093/molbev/msg040)

Telford, M. J., Wise, M. J. \& Gowri-Shankar, V. 2005 Consideration of RNA secondary structure significantly improves likelihood-based estimates of phylogeny: examples from the bilateria. Mol. Biol. Evol. 22, 1129-1136. (doi:10. 1093/molbev/msi099)

Turbeville, J. M., Schulz, J. R. \& Raff, R. A. 1994 Deuterostome phylogeny and the sister group of the chordates: evidence from molecules and morphology. Mol. Biol. Evol. 11, 648-655.

Wada, H. \& Satoh, N. 1994 Details of the evolutionary history from invertebrates to vertebrates, as deduced from sequences of $18 \mathrm{~S}$ rDNA. Proc. Natl Acad. Sci. USA 91, 1801-1804. (doi:10.1073/pnas.91.5.1801)

Wang, D. Y., Kumar, S. \& Hedges, S. B. 1999 Divergence time estimates for the early history of animal phyla and the origin of plants, animals and fungi. Proc. R. Soc. B 266, 163-171. (doi:10.1098/rspb.1999.0617)
Winchell, C. J., Sullivan, J., Cameron, C. B., Swalla, B. J. \& Mallatt, J. 2002 Evaluating hypotheses of deuterostome phylogeny and chordate evolution with new LSU and SSU ribosomal DNA data. Mol. Biol. Evol. 19, 762-776.

Wray, G. A., Levinton, J. S. \& Shapiro, L. S. 1996 Molecular evidence for deep Precambrian divergences among metazoan phyla. Science 274, 568-573. (doi:10.1126/ science.274.5287.568)

Xian-Guang, H., Aldridge, R. J., Siveter, D. J., Siveter, D. J. \& Xiang-Hong, F. 2002 New evidence on the anatomy and phylogeny of the earliest vertebrates. Proc. R. Soc. B 269, 1865-1869. (doi:10.1098/rspb.2002.2104)

Xian-Guang, H., Bergström, J., Xiao-Ya, M. \& Jie, Z. G. 2006 The Lower Cambrian Phlogites Luo \& $\mathrm{Hu}$ reconsidered. GFF 128, 47-51.

Yang, Z. \& Rannala, B. 2006 Bayesian estimation of species divergence times under a molecular clock using multiple fossil calibrations with soft bounds. Mol. Biol. Evol. 23, 212-226. (doi:10.1093/molbev/msj024)

Yokobori, S., Oshima, T. \& Wada, H. 2005 Complete nucleotide sequence of the mitochondrial genome of Doliolum nationalis with implications for evolution of urochordates. Mol. Phylogenet. Evol. 34, 273-283. (doi:10.1016/j.ympev.2004.10.002)

Yu, J. K., Satou, Y., Holland, N. D., Shin, I. T., Kohara, Y., Satoh, N., Bronner-Fraser, M. \& Holland, L. Z. 2007 Axial patterning in cephalochordates and the evolution of the organizer. Nature 445, 613-617. (doi:10.1038/ nature05472)

Zeng, L. \& Swalla, B. J. 2005 Molecular phylogeny of the protochordates: chordate evolution. Can. F. Zool. 83, 24-33. (doi:10.1139/z05-010)

Zeng, L., Jacobs, M. W. \& Swalla, B. J. 2006 Coloniality has evolved once in stolidobranch ascidians. Integr. Comp. Biol. 46, 255-268. (doi:10.1093/icb/icj035)

Zhang, X. G. \& Xian-Guang, H. 2004 Evidence for a single median fin-fold and tail in the Lower Cambrian vertebrate, Haikouichthys ercaicunensis. F. Evol. Biol. 17, 1162-1166. (doi:10.1111/j.1420-9101.2004.00741.x) 